\title{
Assessment of psychiatric comorbidities and sociodemographic profiles of the patients referred to the general hospital psychiatric unit of a tertiary care hospital in Kolkata, West Bengal
}

\author{
Arijit Mondal', Soumi Ghosh², Uday Sankar Mandal ${ }^{3}$, Dwaipayan Saha ${ }^{4}$ \\ ${ }^{1}$ Senior Resident, ${ }^{2}$ Junior Resident, ${ }^{4}$ Medical Officer, Department of Psychiatry, Institute of Psychiatry - A Centre of \\ Excellence, 7 D L Khan Road, Kolkata - 700 025, West Bengal, India, ${ }^{3}$ Assistant Professor, Department of Psychiatry, \\ R. G. Kar Medical College and Hospital, Kolkata, West Bengal, India
}

\section{A B S T R A C T}

Background: According to the previous studies, psychiatric symptoms are high in patients with physical illness, but the referral rates are much below expectation. Aims and Objectives: Here a descriptive cross-sectional study has been conducted using self designed semi structured proforma to asses the socio demographic profile and psychiatric diagnosis of patient with physical illness referred from other departments in a tertiary medical care centre for consultation liaison (C-L) psychiatry care. Materials and Methods: The study population consists of the patients referred to psychiatry department for consultation purpose from all the other departments in a 4 months period. The data were collected on a self designed semi structured pro forma and all the diagnosis were made according to International Classification of Disease -10 (ICD-10) criteria. Analysis has been done using descriptive statistics. Results: A total numbers of 203 patient has been referred to psychiatry department during the study period. Among them 144 were inpatient and 59 were outdoor based referral. Majority were female, married. The maximum referral were from general medicine department followed by neuromedicine. Most common reason of referral being suicidal attempt by different means followed by patients having depressive features. The most common psychiatric diagnosis was depression followed by delirium. Conclusion: C-L psychiatry plays a significant role in better evaluation and management of patients with psychiatric comorbidities referred from non-psychiatric departments.

Access this article online

Website:

http://nepjol.info/index.php/AJMS DOI: 10.3126/ajms.v12i11.38561

E-ISSN: 2091-0576

P-ISSN: 2467-9100

Copyright (c) 2021 Asian Journal of Medical Sciences

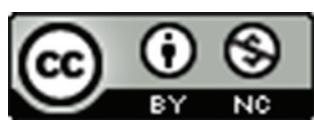

This work is licensed under a Creative Commons Attribution-NonCommercial 4.0 International License.

Key words: Consultation-liaison; Sociodemographic profile; Psychiatric referral;

Psychiatric comorbidity

\section{INTRODUCTION}

Consultation-liaison (C-L) psychiatry is a relatively new subspecialty of psychiatry in Indian health sectors, which provides psychiatric advice on a referral basis and acts as a liaison which focuses on the connection between the medical and psychiatric disorders. ${ }^{1}$ It incorporates clinical services, teaching practice, and research activities of psychiatrists in the non-psychiatric department of a general hospital setup. ${ }^{2}$ It consists of two pillars, first being the consultation, where expert advice is being provided to the patients in a referral basis and the second of liaison, where the consultant psychiatrist mediates between patients and the clinical team and imparts educational or facilitative functions. ${ }^{3,4}$

Currently, C-L service in India mainly focuses on the consultation model, where the psychiatrist evaluates and 
assesses the referred patient and provides management either inpatient or on an outpatient basis. ${ }^{5}$ The majority of the referred patient's falls into the categories mentioned as: (a) Primary medical illness with comorbid psychopathology; (b) psychiatric illness directly resulting from a primary organic condition, ex. delirium; (c) medically unexplained physical symptoms, such as somatoform and functional disorders; and (d) psychiatric emergencies such as suicidal attempt by different means, admitted to medical/surgical units. $^{2}$

In spite of comorbid psychopathology among patients from non-psychiatric departments being quite high in India (31-34\% among inpatients and $18.32-53.7 \%$ among outpatients), the referral rates in India (0.15-1.54\%) are much lower in comparison to the developed countries $(2.2-1.2 \%)$ in the world. ${ }^{3,6}$ The reasons can be of many such as, social stigma regarding psychiatric illness, giving primary importance to physical illness neglecting the psychiatric symptoms, poor psychiatric awareness among patients, family members, as well as the health-care providers. ${ }^{7} \mathrm{By}$ the implementation of C-L psychiatry services on a wider basis, this discrepancy can be overcome to a large extent.

The co-occurence of general medical disorder and psychiatric illness is one of the most common and disabling combinations, with approximately $30 \%$ of individuals with comorbidities are having both of physical and psychiatric disorders. ${ }^{8}$ According to Levenson et al., patients with associated psychopathology had longer duration of hospital stay, more chance to undergo interventional procedures, overburdening the health-care resources, and poorer prognosis.' A timely psychiatric intervention in these cases can improve the outcome including mortality and morbidity.

Keeping in mind the above-mentioned facts and the prerequisite for "a superior and more appropriate management," C-L psychiatry has emerged as the need of the hour for a wholesome therapeutic approach. The data available show the underutilized status of C-L services in health-care sectors of India and also the need for the improvement in future. ${ }^{10}$

The study conducted here aims to assess sociodemographic profile and psychiatric comorbidities of patients referred for consultation services from non-psychiatric departments of a tertiary care hospital.

\section{MATERIALS AND METHODS}

The study includes all the indoor and outdoor patients referred to the department of psychiatry during or after
OPD hours for C-L psychiatry from other departments of the hospital. The study period was from June 12, 2020, to September 12, 2020, that is, over a period of 4 months. The diagnosis was made according to the International Classification of Diseases, Tenth Edition (ICD10). The details recorded include sociodemographic profiles, department and mode of referral (inpatient or outpatient), reason of referral, presenting complaint, and final psychiatric diagnosis (according to ICD-10). The data collected on selected days of the week (Wednesday and Friday) with the help of a self-designed semistructured pro forma after taking proper consent from the patients or legally appropriate caretaker. Eligibility criteria include all the inpatient or outpatient referral from departments other than psychiatry of either sex and no age limit was set. Exclusion criteria - convicted patient, patient without any attendant, under trial patient, and patients admitted by court of law due to lack of reliable informant. The study was approved by ethical committee of the institute. Analysis was done using descriptive statistics.

\section{RESULTS}

\section{Sociodemographic status}

A total of 203 patients were assessed after being referred from various departments. Out of them, 108 (53.2\%) were female and $95(46.8 \%)$ were male. Patients age was in a range from 10 years to 89 years with the mean age being 36.33 years, with a standard deviation of 12.05. Out of them, 137 people were married (67\%), 53 were unmarried $(26 \%)$, 9 were widowed $(4.4 \%)$, and 4 were separated from their spouses $(1.9 \%)$. Out of 203 patients, 79 belonged to urban (38\%), 67 from rural $(33 \%)$, and $57(28 \%)$ from semi-urban type of residency. Among them, 85 (41.8\%) person belonged to joint family, 59 belonged to nuclear family (29\%), and 59 from extended nuclear family $(29 \%)$. Regarding the education status, 5 of them were illiterate $(2.5 \%)$, 66 were educated till primary school $(32.5 \%), 74$ were till high school (36.4\%), 53 (26.1\%) of them completed graduation, and 5 (0.024) of them completed their post-graduation. Among them, 85 (42\%) person belong to joint family, 59 belong to nuclear family $(29 \%)$, and 59 from extended nuclear family $(29 \%)$. Regarding the occupational status, majority, that is, $72(35.4 \%)$ were homemaker, $40(19.7 \%)$ were businessman, 24 (11.8\%) were unskilled worker, $22(10.8 \%)$ were unemployed, $21(10.3 \%)$ were student, $19(9.3 \%)$ were skilled worker, and rest $5(2.4 \%)$ were clerical worker.

All the demographic variables are shown in Table 1. 


\begin{tabular}{|c|c|c|}
\hline Variable & Frequency $(n=203)$ & Percentage \\
\hline Age & $\begin{array}{l}\text { Mean age } \sim 36.33 \\
\quad(\text { SD 12.05) }\end{array}$ & \\
\hline Below 60 years & 181 & 89.1 \\
\hline At or above 60 years & 22 & 10.9 \\
\hline \multicolumn{3}{|l|}{ Sex } \\
\hline Male & 95 & 46.8 \\
\hline Female & 108 & 53.2 \\
\hline \multicolumn{3}{|l|}{ Marital status } \\
\hline Married & 137 & 67.5 \\
\hline Unmarried & 53 & 26.1 \\
\hline Widowed & 9 & 4.4 \\
\hline Separated & 4 & 1.9 \\
\hline \multicolumn{3}{|l|}{ Residency } \\
\hline Urban & 79 & 38 \\
\hline Semi-urban & 57 & 28 \\
\hline Rural & 67 & 33 \\
\hline \multicolumn{3}{|l|}{ Educational status } \\
\hline Illiterate & 5 & 2.5 \\
\hline Primary school & 66 & 32.5 \\
\hline High school & 74 & 36.4 \\
\hline Graduate & 53 & 26 \\
\hline Postgraduate & 5 & 0.024 \\
\hline \multicolumn{3}{|l|}{ Family type } \\
\hline Joint & 85 & 42 \\
\hline Nuclear & 59 & 29 \\
\hline Extended nuclear & 59 & 29 \\
\hline \multicolumn{3}{|l|}{ Occupation } \\
\hline Homemaker & 72 & 35.46 \\
\hline Business & 40 & 19.7 \\
\hline Unskilled worker & 24 & 11.8 \\
\hline Unemployed & 22 & 10.8 \\
\hline Student & 21 & 10.34 \\
\hline Skilled worker & 19 & 9.35 \\
\hline Clerical worker & 5 & 2.46 \\
\hline
\end{tabular}

Source of referral

Among the total 203 referrals, 144 (70.93\%) were inpatient- and the rest $59(29.06 \%)$ were outpatient-based referral. The most common source of referral is from general medicine $(21.1 \%)$ followed by neuromedicine $(9.8 \%)$ and gynecology and obstetrics department (7.8\%). Other departments from which referral came were cardiology (6.4\%), trauma care center (6.4\%), gastroenterology (5.9\%), emergency observation ward (5.4\%), general surgery $(4.9 \%)$, intensive care unit $(4.9 \%)$, burn ward $(4.4 \%)$, dermatology $(4.4 \%)$, otorhinolaryngology $(3.4 \%)$, chest medicine $(3.4 \%)$, nephrology $(3.4 \%)$, plastic surgery $(2.9 \%)$, pediatrics $(2.9 \%)$ and rheumatology $(0.98 \%)$, and urology $(0.98 \%)$, as described in Table 2 and Figure 1.

\section{Reason for psychiatric consultation}

The most common reason for seeking psychiatric consultation was suicidal attempts by different means $(n=34,16.7 \%)$ followed by patients with features of anxiety symptoms ( $\mathrm{n}=25,12.3 \%)$, patients with a history of taking psychiatric medications ( $\mathrm{n}=25,12.31 \%)$, acute onset irrelevant talks with behavioral abnormality $(n=23$,

\begin{tabular}{lc}
$\begin{array}{l}\text { Table 2: Distribution according to source of } \\
\text { referral among study subjects }\end{array}$ \\
\hline Source of referral & $\mathbf{n ~ 2 0 3 ~ ( \% )}$ \\
\hline General medicine & $43(21.1)$ \\
Neuro medicine & $20(9.8)$ \\
Gynecology and obstetrics & $16(7.8)$ \\
Cardiology & $13(6.4)$ \\
Trauma care center & $13(6.4)$ \\
Gastroenterology & $12(5.9)$ \\
Emergency observation ward & $11(5.4)$ \\
General surgery & $10(4.9)$ \\
ICU & $10(4.9)$ \\
Burn & $9(4.4)$ \\
Dermatology & $9(4.4)$ \\
ENT & $7(3.4)$ \\
Chest medicine & $7(3.4)$ \\
Nephrology & $7(3.4)$ \\
Plastic surgery & $6(2.9)$ \\
Pediatrics & $6(2.9)$ \\
Rheumatology & $2(0.98)$ \\
Urology & $2(0.98)$ \\
\hline
\end{tabular}

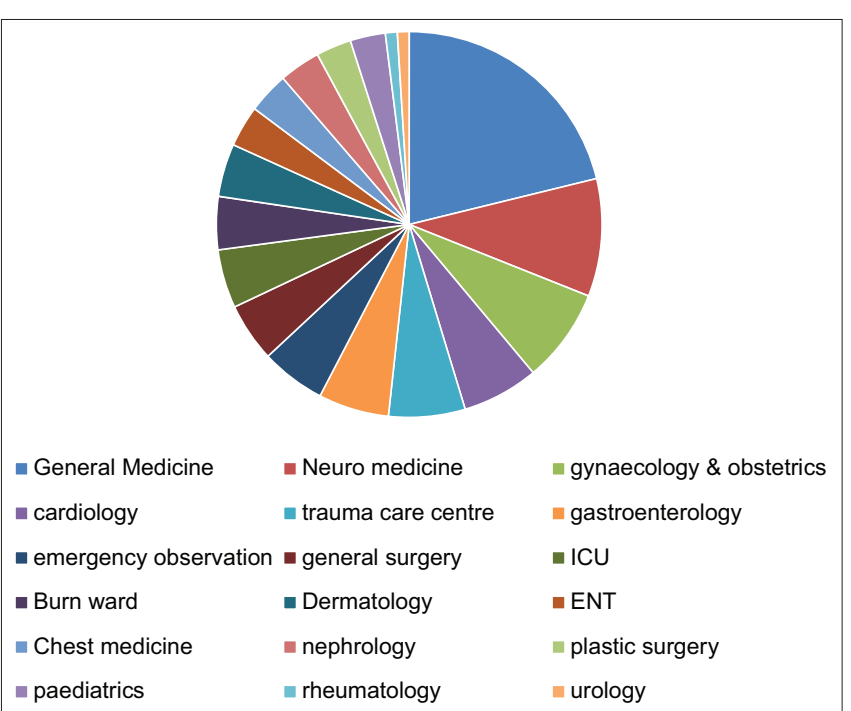

Figure 1: Distribution according to sources of psychiatric referral

$11.33 \%$ ), other causes of referral are medically unexplained physical symptoms ( $\mathrm{n}=19,9.35 \%)$, altered sensorium, restlessness, behavioral abnormality $(\mathrm{n}=17,8.3 \%)$, patients who apparently had neurological symptoms $(\mathrm{n}=15,7.3 \%)$, history of alcohol use disorder ( $\mathrm{n}=11,5.4 \%$ ), abnormal behavior in postpartum period ( $\mathrm{n}=11,5.4 \%)$, patients with depressive features $(\mathrm{n}=8,3.94 \%)$, and history of multiple substance abuse $(\mathrm{n}=4,1.9 \%)$

There was also referral made for psychiatric clearance for renal transplantation surgery $(\mathrm{n}=7,3.4 \%)$ and gender reconstruction surgery $(n=4,1.97 \%)$, as shown in Table 3 :

\section{Final psychiatric diagnosis}

There are wide varieties in psychiatric diagnosis of the patients referred from other departments (Figure 2). 


\begin{tabular}{lc}
$\begin{array}{l}\text { Table 3: Reason of psychiatric consultation } \\
\text { among study subjects }\end{array}$ \\
\hline Reason for consultation to psychiatry & $\mathbf{n ~ 2 0 3 ~ ( p e r c e n t a g e ) ~}$ \\
\hline Suicidal attempts by different means & $34(16.7)$ \\
Features of anxiety symptoms & $25(12.3)$ \\
A history of taking psychiatric medication & $25(12.3)$ \\
Acute onset irrelevant talk with behavioral & $23(11.3)$ \\
abnormality & $19(9.3)$ \\
Medically unexplained physical symptoms & $17(8.3)$ \\
Altered sensorium, restlessness, & \\
behavioral abnormality & $15(7.3)$ \\
Patients with apparently neurological & \\
symptoms & $11(5.4)$ \\
History of alcohol addiction & $11(5.4)$ \\
Abnormal behavior in postpartum period & $8(3.9)$ \\
Patients with depressive features & $7(3.4)$ \\
Clearance for renal transplant surgery & $4(1.9)$ \\
History of multiple substance abuse & $4(1.9)$ \\
Clearance for gender reconstruction & \\
surgery & \\
\hline
\end{tabular}

A number of patients received nil psychiatric diagnosis $(\mathrm{n}=11,5.4 \%)$. Other than that most common psychiatric diagnosis was depressive episode ( $\mathrm{n} \sim 27,13.3 \%$ ), followed by delirium ( $\mathrm{n} \sim 19,9.3 \%)$, other mental disorder due to brain damage ( $\mathrm{n} \sim 18,8.8 \%)$, somatization disorder $(\mathrm{n} \sim 16$, $7.88 \%$ ), alcohol dependence syndrome ( $\mathrm{n} \sim 14,6.89 \%$ ), bipolar affective disorder ( $\mathrm{n} \sim 10,4.9 \%)$, unspecified dementia ( $\mathrm{n} \sim 10,4.9 \%)$, mixed anxiety and depressive disorder ( $\mathrm{n} \sim 9,4.43 \%)$, mental and behavioral disorder associated with the puerperium ( $\mathrm{n} \sim 9,4.43 \%$ ), adjustment disorder ( $\mathrm{n} \sim 8,3.9 \%)$, emotionally unstable personality disorder ( $\mathrm{n} \sim 7,3.4 \%)$, dissociative (conversion) disorder $(\mathrm{n} \sim 6,2.9 \%)$, schizophrenia $(\mathrm{n} \sim 6,2.9 \%)$, acute transient psychotic disorder $(\mathrm{n} \sim 6,2.9 \%)$, erectile dysfunction $(\mathrm{n} \sim 6,2.9 \%)$, conduct disorder $(\mathrm{n} \sim 5,2.46 \%)$, dissocial personality disorder $(n \sim 5,2.46 \%)$, habit and impulse control disorder ( $\mathrm{n} \sim 3,1.47 \%)$, and mental and behavioral disorder due to multiple drug use, and use of other psychoactive substances $(\mathrm{n} \sim 3,1.47 \%)$, as shown in Table 4.

\section{Psychiatric diagnosis versus gender}

Psychiatric diagnosis according to ICD-10 was analyzed on the basis of total patients referred (Figure 3) and gender (Figure 4), it was found that organic disorders (F00-F09) and mental and behavioral disorder due to psychoactive substance use were more common in men ( $\mathrm{n} \sim 34,72.34 \%$ ), whereas, schizophrenia, schizotypal, and delusional disorder (F20-F29), mood disorders (F30-F39), neurotic, stress-related and somatoform disorders (F40-F48), behavioral syndrome associated with physiological disturbances and physical factors (F50-F59), and disorders of adult personality and behavior (F60-F69) all were more common in female, as shown in Table 5 .

\begin{tabular}{lc}
$\begin{array}{l}\text { Table 4: Final psychiatric diagnosis of the study } \\
\text { subjects }\end{array}$ \\
\hline Psychiatric diagnosis & n 203 (percentage) \\
\hline Depressive episode & $27(13.3)$ \\
Delirium & $19(9.3)$ \\
Other mental disorder due to brain & $18(8.8)$ \\
damage & $16(7.88)$ \\
Somatoform disorder & $14(6.89)$ \\
Alcohol dependence syndrome & $10(4.9)$ \\
Bipolar affective disorder & $10(4.9)$ \\
Unspecified dementia & $9(4.43)$ \\
Mixed anxiety and depressive disorder & $9(4.43)$ \\
Mental and behavioral disorder & \\
associated with the puerperium & $8,(3.9)$ \\
Adjustment disorder & $7(3.4)$ \\
Emotionally unstable personality disorder & $6(2.9)$ \\
Dissociative (conversion) disorder & $6(2.9)$ \\
Schizophrenia & $6(2.9)$ \\
Acute transient psychotic disorder & $6(2.9)$ \\
Erectile dysfunction & $5(2.46)$ \\
Conduct disorder & $5(2.46)$ \\
Panic disorder & $5(2.46)$ \\
Dissocial personality disorder & $3(1.47)$ \\
Trichotillomania/habit and impulse control & \\
disorder & $3(1.47)$ \\
Mental and behavioral disorder due & \\
to multiple drug use and use of other & \\
psychoactive substances & \\
\hline &
\end{tabular}

\begin{tabular}{|c|c|c|c|}
\hline $\begin{array}{l}\text { Psychiatric } \\
\text { diagnosis (ICD-10 } \\
\text { CDDG diagnostic } \\
\text { codes) }\end{array}$ & $\begin{array}{c}\text { Female } \\
\text { (percentage) }\end{array}$ & $\begin{array}{c}\text { Male } \\
\text { (percentage) }\end{array}$ & $\begin{array}{c}\text { Total } \\
(n \sim 203)\end{array}$ \\
\hline F00-F09 & $13(27.65)$ & $34(72.34)$ & 47 \\
\hline F10-F19 & $0(0)$ & $15(100)$ & 15 \\
\hline F20-F29 & $8(66.6)$ & $4(33.33)$ & 12 \\
\hline F30-F39 & $32(69.56)$ & $14(30.43)$ & 46 \\
\hline F40-F48 & $29(80.55)$ & $7(19.44)$ & 36 \\
\hline F50-F59 & $9(60)$ & $6(40)$ & 15 \\
\hline F60-F69 & $9(60)$ & $6(40)$ & 15 \\
\hline
\end{tabular}

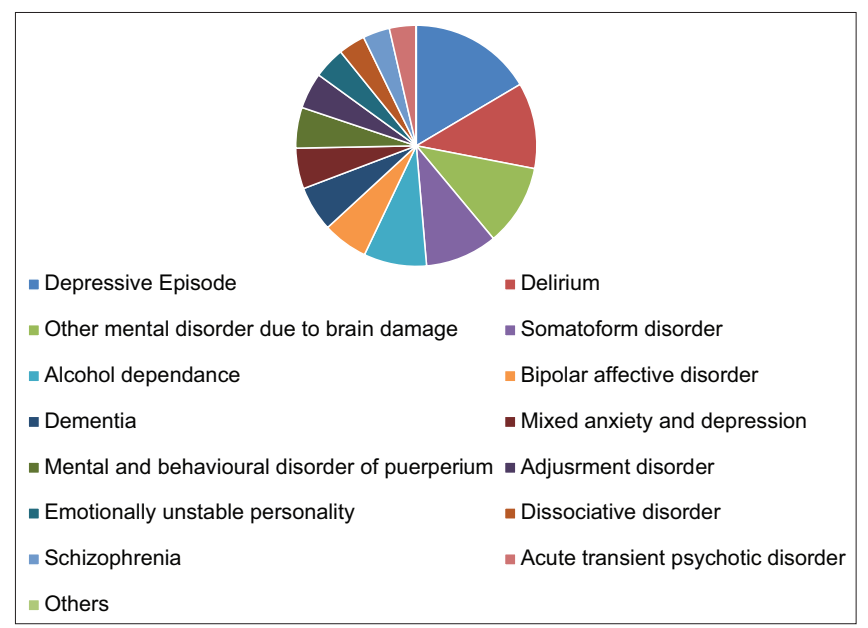

Figure 2: Final psychiatric diagnosis of the study subjects 


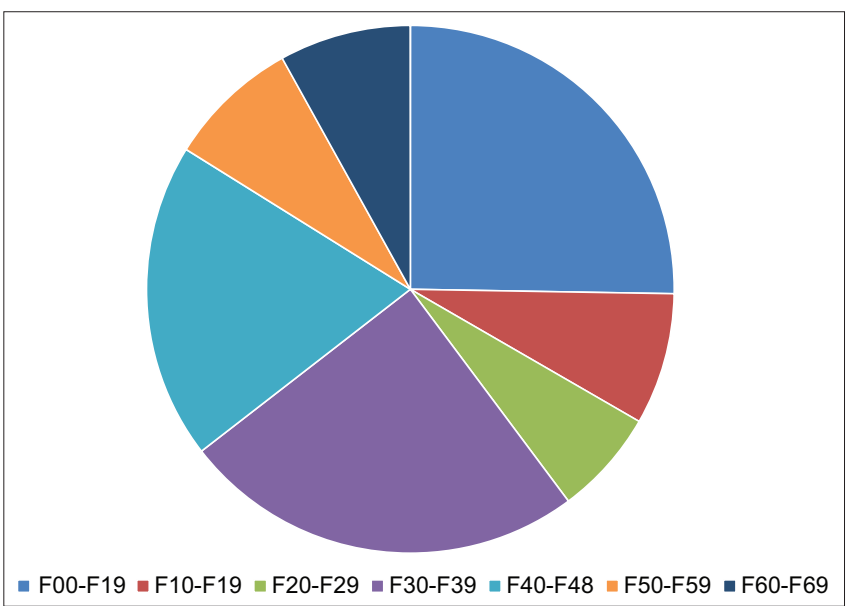

Figure 3: Psychiatric diagnosis according to ICD-10 classification. ICD: International classification of diseases, tenth edition

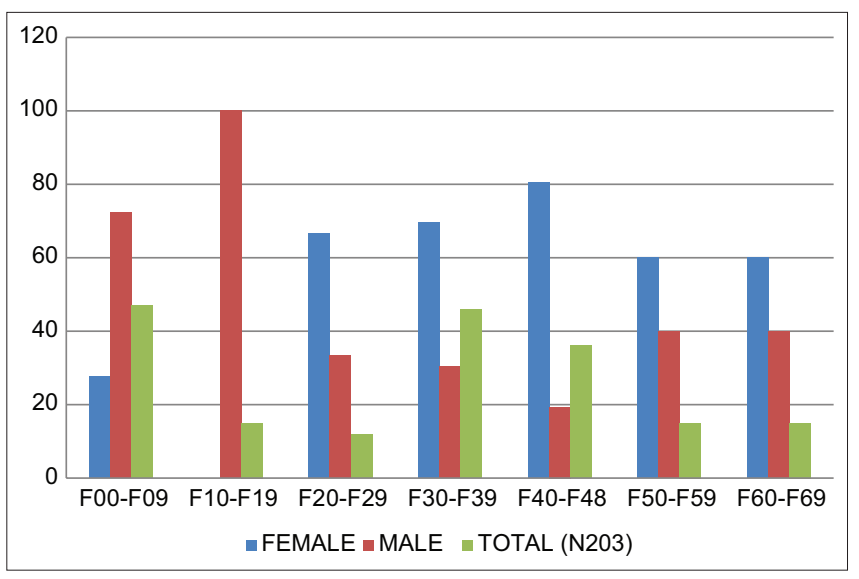

Figure 4: Psychiatric diagnosis versus gender among study subjects

\section{DISCUSSION}

C-L psychiatry is a relatively newer branch of psychiatry that often used synonymously with the term "psychosomatic medicine," a concept gave by Felix Deutsch on the year 1922. The basic aim is to bring psychiatrists in close proximity to other health-care specialist to assess psychiatric comorbidities and to provide optimal health care as well as indulging in research activities. ${ }^{11}$ The very beginning of C-L psychiatry concept in India started on 1933 with the establishment of first General Hospital Psychiatry Unit by Dr. Girindra Sekhar Bose at the premise of R.G. Kar Medical College in Kolkata which is the center of our current study as well. ${ }^{11}$ However, till now, the branch is not been utilized of its full potential. According to the previous study in India, majority of C-L psychiatry services are provided as an on call basis, where after receiving an referral patient file, the on-duty psychiatrist of the day attends the patient of the respective department or the patient is sent to the psychiatric outdoor along with the attendant regarding evaluation and opinion. In majority of the institutes, it's the junior resident $(60 \%)$ who attends the referral followed by senior residents $(21.1 \%)$ and faculty members (18.9\%). The departments of clinical psychology, psychiatric social workers, and psychiatric nursing are also a part of C-L psychiatry team in a very few premiere institutes in India. ${ }^{12}$

In the current study, there are total 203 referrals in the 4-month duration. Among them, 144 were inpatient- and 59 were outpatient-based referral. The mean age group of referral is 36.33 years, with $22(10.83 \%)$ of patients has age ranging from 60 years and above which is bit on higher side than a previous study conducted in India and rest 181 (89.1\%) of them has age below 60 years, similar results found in other studies as well., ${ }^{2,8}$ Majority of them were female $(53.2 \%)$, while some other studies conducted before, shows a male predominance. ${ }^{8,13}$ Most of the patients were from urban $(38 \%)$, joint family $(85 \%)$, married (67\%), homemaker (33.99\%), and studied till high school $(36.4 \%)$.

The most common source of referral being department of general medicine (21.1\%) followed by department of neuromedicine $(9.8 \%$ ), which is also a common finding in earlier studies done in India and other countries as well. ${ }^{10,14,15}$ The reason for this is poor knowledge regarding psychiatric signs and symptoms and the social stigma, majority of the patients prefers to approach to the general medicine department and the general physicians rather than psychiatrists. ${ }^{8,10}$ The reason for high referral to neuromedicine department attributes to similar clinical presentation of psychiatric disorders such as pseudo-seizures, dissociative disorders to that of various neurological diseases. ${ }^{16,17}$ There were significant less number of referral from general surgery ( $\mathrm{n} \sim 10,4.9 \%$ ), than what found in other previous studies., ${ }^{8,10}$

Most common reason of referral was suicidal attempts by different means ( $\mathrm{n} \sim 34,16.7 \%$ ), it also includes deliberate self-harms and parasuicidal attempts, which reflects the implementation of Mental Healthcare Act that mandates psychiatric consultation in suicidal attempts. ${ }^{18}$ Other common reasons for referral were patients having anxiety symptoms ( $\mathrm{n} \sim 25,12.31 \%)$, patients with a history of taking psychiatric medications, that is, a history of known psychiatric illness ( $\mathrm{n} \sim 25,12.31)$. Referral for alcohol and other substance addiction was 7.3\% ( $\mathrm{n} \sim 15,11$ for alcohol only and 4 for multiple substance abuse), other studies conducted in India by Goyal et al., and Keertish et al., shows 11.3\%-14.5\% referrals for substance abuse. ${ }^{2,13}$ A study conducted by Bagadia et al., has reported most common reason for psychiatric referral being altered sensorium and behavioural abnormality (21.65\%) followed by alcohol 
dependence $(18.47 \%)$, past history of psychiatric illness $(28.6 \%) .^{3}$ Another study in India by Bhogale et al., shows unexplained somatic symptoms for the most common reason for referral $(64.44 \%) .{ }^{14}$ Being a super speciality tertiary care teaching hospital, there are also some referral for psychiatric clearance before renal transplantation surgery ( $\mathrm{n} \sim 7,3.4 \%$ ), and gender reconstruction surgery $(\mathrm{n} \sim 4,1.97 \%)$ which is much lower than a previous study conducted at tertiary care hospital of India. ${ }^{2}$ It somewhere reflects the underutilization of the facilities.

According to psychiatric diagnostic point of view (ICD-10 criteria), major depressive disorder (13.3\%) and delirium $(9.3 \%)$ were the most common to be found, in contrary to some other studies conducted in India that shows somatoform disorders and neurotic disorders to be the most common diagnosis. ${ }^{13}$ When diagnosis was assessed according to ICD-10 categories, it is found that organic disorders are to be the most common diagnosis $(n \sim 47$, $23.15 \%$ ) followed by mood (affective) disorders ( $\mathrm{n} \sim 46$, $22.66 \%)$.

A number of patients ( $\mathrm{n} \sim 11,5.4 \%)$ received nil psychiatric diagnosis and most of them were person who required psychiatric clearance for either renal transplant surgery or gender reconstruction surgery. This finding is much lower that found in the previous studies in India., ${ }^{2,3}$

With the increasing concern regarding mental health in association with physical health, C-L psychiatry plays an important role to bridge the gap between the two sectors. It can also play a major role to extend mental health services on primary care level and provide a great help to the primary health care workers by increasing the awareness regarding recognizing early signs and symptoms and management of psychiatric illnesses. ${ }^{5}$ They can also be considered the most potential persons to provide telepsychiatry services at remote areas over the phone where there is a scarcity of psychiatric services.

\section{Limitations of the study}

The study has all the limitations of being a cross-sectional study, also as it is been conducted over a period of 4 months which is a short duration and also on specific days of the week. Hence, the results cannot be generalized to other hospitals and on general community.

\section{CONCLUSION}

Consultation-liaison psychiatry is a new emerging branch of psychiatry in India to bridge the gap between mental and physical healthcare thus providing optimal care to the patients. There is still lack of knowledge and awareness among healthcare worker regarding this sub speciality and the purpose of our study is to increase awareness regarding the demand and the necessity of the consultation-liaison psychiatry services in our country for better integrated management of the patients in future.

\section{REFERENCES}

1. Keerthy R, Sivin PS, Soumya P, Sheena V, Joice G, Vijayalal V, et al. Consultation liaison psychiatry diagnostic concordance between referring physician and psychiatrist. Kerala J Psychiatry. 2020;33(1):16-26.

https://doi.org/10.30834/KJP.33.1.2020.182

2. Goyal SG, Sagar R and Sharan P. Sociodemographic profile and psychiatric diagnosis of patients referred to consultationliaison psychiatric services of general hospital psychiatric unit at a tertiary care center. J Mental Health Hum Behav. $2017 ; 22: 45$.

https://doi.org/10.4103/0971-8990.210709

3. Patra P, Divinakumar KJ, Prakash J, Patra B and Chakraborty R. Clinico-psycho-social profile of patients brought under consultation-liaison psychiatry care in a large tertiary care referral hospital. Ind Psychiatry J. 2017;26(1):24.

https://doi.org/10.4103/ipj.ipj_13_17

4. Singh PK, Prakash SO and Vinay K, editors. IPS Textbook of Undergraduate Psychiatry. $1^{\text {st }}$ ed., Vol. 1. New Delhi: Jaypee Brothers Medical Publishers; 2020. p. 275-276.

5. Grover S. State of consultation-liaison psychiatry in India: Current status and vision for future. Indian J Psychiatry. 2011;53(3):202. https://doi.org/10.4103/0019-5545.86805

6. 6. P Sam S, Reji K, Thomas S, Varughese S, Geo J, Vijayan V, et al. Consultation Liaison Psychiatry - Diagnostic concordance between referring physician and psychiatrist. KJP [Internet]. 2020 Feb 21 [cited 2020 Oct 19];33(1). https://doi.org/10.30834/KJP.33.1.2020.182

7. Grover S, Sahoo S, Aggarwal S, Dhiman S, Chakrabarti S and Avasthi A. Reasons for referral and diagnostic concordance between physicians/ surgeons and the consultation-liaison psychiatry team: An exploratory study from a tertiary care hospital in India. Indian Journal of Psychiatry. 2017;59(2):170. https://doi.org/10.4103/psychiatry.IndianJPsychiatry_305_16

8. Mudgal V, Rastogi P, Niranjan V and Razdan R. Pattern, clinical and demographic profile of inpatient psychiatry referrals in a tertiary care teaching hospital: a descriptive study. Gen Psychiatr. 2020;33(4):e100177-e100177. https://doi.org/10.1136/gpsych-2019-100177

9. Levenson JL, Hamer RM and Rossiter LF. Relation of psychopathology in general medical inpatients to use and cost of services. Am J Psychiatry. 1990;147(11):1498-1503.

10. Tekkalaki B, Tripathi A, Arya A and Nischal A. A descriptive study of pattern of psychiatric referrals and effect of psychiatric intervention in consultation-liaison set up in a tertiary care center. Indian Journal of Social Psychiatry. 2017;33:165. https://doi.org/10.4103/0971-9962.209181

11. Grover $S$ and Avasthi A. Consultation-liaison psychiatry in India: Where to go from here? Indian J Psychiatry. 2019;61(2):117.

12. Grover $S$ and Avasthi A. Consultation-liaison psychiatry services: A survey of medical institutes in India. Indian J Psychiatry. 2018;60(3):300-306

https://doi.org/10.4103/psychiatry.IndianJPsychiatry_256_17

13. Keertish N, Sathyanarayana MT, Kumar BG, Singh N and Udagave K. Pattern of psychiatric referrals in a tertiary 
care teaching hospital in Southern India. J Clin Diagn Res. 2013;7(8):1689-1691.

14. Bhogale GS, Katte RM, Heble SP, Sinha UK and Patil BA. Psychiatric referrals in multispeciality hospital. Indian $\mathrm{J}$ Psychiatry. 2000;42(2):188-194.

15. Parkar SR and Sawant NS. Liaison psychiatry and Indian research. Indian J Psychiatry. 2010;52(7):386.

https://doi.org/10.4103/0019-5545.69274

16. Crimlisk HL, Bhatia K, Cope H, David A, Marsden CD and Ron MA Slater revisited: 6 year follow up study of patients with medically unexplained motor symptoms. BMJ. 1998;316(7131):582-586. https://doi.org/10.1136/bmj.316.7131.582

17. Stone J, Carson A, Duncan R, Coleman R, Roberts R, Warlow C, et al. Symptoms 'unexplained by organic disease' in 1144 new neurology out-patients: How often does the diagnosis change at follow-up? Brain. 2009;132(10):2878-2888. https://doi.org/10.1093/brain/awp220

18. Vadlamani LN and Gowda M. Practical implications of mental healthcare act 2017: Suicide and suicide attempt. Indian J Psychiatry. 2019;61(Suppl 4):S750-S755.

\section{Authors' Contributions:}

AM-Data collection and review of manuscript; SG-Preparation of manuscript; USM-Concept and design of the study; DS-Data analysis.

Work attributed to:

R. G. Kar Medical College and Hospital, 1 Khudiram Bose Sarani, Kolkata - 700 004, West Bengal, India.

ORCID ID:

Dr. Arijit Mondal- (D) https://orcid.org/0000-0001-5504-0577

Dr. Soumi Ghosh- (i) https://orcid.org/0000-0001-9185-1238

Dr. Uday Sankar Mandal- (1) https://orcid.org/0000-0002-2886-8333

Dr. Dwaipayan Saha- (iD https://orcid.org/0000-0003-3255-5572

Source of Funding: None, Conflicts of Interest: None. 